\title{
Educational Action Research as the quest for virtue in teaching
}

\author{
John Elliott, Centre for Applied Research in Education, University of \\ East Anglia, U.K.
}

\begin{abstract}
$\underline{\text { Abstract }}$
Curriculum aims often remain unrealised aspirations. This is because the values and principles implicit in them fail to get articulated in forms that can effectively inform and guide the practice of teaching. Ideas such as 'learner-centred education', 'independent/autonomous learning', 'selfdirected learning', 'enquiry/discovery learning', 'collaborative learning', 'active learning' and 'learning with understanding' refer to critical aspects of the learning process rather than its outcomes. While often enthusiastically embraced by teachers, they rarely get realised in appropriate forms of virtuous action. Such is the power of an outcomesbased model of teaching and learning to shape the practice of teaching.
\end{abstract}

This paper cites examples of curriculum design that specify the pedagogical values and principles implicit in various educational aims, and show how they can provide a basis for practical experiments by teachers in their classrooms and schools, in a quest to transform their teaching into concrete forms of virtuous action. Indeed the paper depicts a number of actual action research projects in which teachers generated some common insights into how to transform their teaching into the practice of virtue in education. It also explores the role of theoryinformed action research in developing teaching as a virtuous form of action.

\section{Introduction}

Lawrence Stenhouse's idea of 'the teacher as a researcher' who engaged in systematic self-study "through the study of the work of other teachers and through the testing of ideas by classroom research procedures" (see Stenhouse 1975, pp. 142-165) emerged in the course of his work as Director of the Schools Council Humanities Curriculum Project (196772). The design of the project followed what Stenhouse (1975 pp. 84-97) called a 'process model' of curriculum design. It was deliberately cast as an alternative to the increasingly fashionable model of 'rational curriculum planning' or 'planning by behavioural objectives'. Much of the inspiration for the 'process model' stemmed from R.S. Peters' work in Philosophy of Education (see Peters 1966, pp. 23-45, and 1973, pp. 1177). Peters argued that 'Education' was a normative concept, and that the discourse about its aims focussed on clarifying the values and principles that defined it as a worthwhile process. Educational discourse about aims 
was not to be confused with an instrumental discourse about the extrinsic purposes of education. Following Peters, Stenhouse proceeded to specify an aim of teaching in the humanities field, which could then be analysed into principles that specified a form of procedure in the classroom, rather than into a set of precise and measurable behavioural objectives. This 'process model' of curriculum design furnished criteria for judging the quality of the interactions within the teaching-learning milieu. Aims such as 'learner-centred education', 'independent/autonomous learning', 'selfdirected learning', 'enquiry/discovery learning', 'collaborative learning' and 'active learning' provide examples of such criteria and refer to qualities of the learning process rather than its outcomes. I would claim that these aims depict critical aspects of a more general and holistic curriculum aim, that of 'learning with understanding.'

The 'process model' enables teachers to create an ethical space for learning in which the individuality and creativity of the learner as an autonomous subject is respected and $\mathrm{s}(\mathrm{he})$ is allowed to take responsibility for their learning. Within this model's frame of reference the concept of 'understanding' constitutes an ethical perspective on learning that implies a dynamic view of 'knowledge' as provisional and open to speculation and doubt. In contrast the 'space for learning' within the 'behavioural objectives model' is shaped by a technical rationality that gives the teacher technical control over the learning process and renders him/her responsible/accountable for its outcomes. Within this model's frame of reference 'understanding' as a concept is subordinated to a view of knowledge as fixed and indubitable fact.

The 'process model' developed by Stenhouse challenges teachers to discern how best to realise a curriculum aim and its associated principles of procedure in action within a particular pedagogical context. Such aims and procedures can, however, be enthusiastically embraced by teachers without being transformed into appropriate forms of action. They provide a practical orientation for the teacher without prescribing specific actions. From a Stenhousian perspective, educational values (in the form of aims and principles of procedure) are open to a diversity of contexts and in any particular context their transformation into forms of action is a task for teachers' research. This idea of 'the teacher as a researcher' must be carefully distinguished from notions of 'practitioner research' that have subsequently been shaped by the 'behavioural objectives model' of curriculum design, where teachers are expected to discern within their particular contexts of practice 'what works' to bring about desired behavioural outcomes. Here 'teaching methods' have no intrinsic value as 
forms of action in themselves. Their value is simply instrumental as an effective means of producing extrinsic and measurable outcomes.

The relationship between ends and means in the 'process model' is significantly different from the 'behavioural objectives model'. In the latter the ends can be defined independently of the means chosen to bring them about. In the former the aims and principles are defined by the actions taken to realise them. One gets clearer about the ends by discerning the appropriate means of realising them in action. Ends and means are joint objects of reflection in teachers' action research.

I have argued (see Elliott 1991 p. 138; 2007a pp. 107-8; 2007b pp.150-2) that educational action research, as a process of inquiry in which the values that are constitutive features of a worthwhile process of education are transformed into concrete actions (means), involves what Aristotle in the Nichomachean Ethics called phronesis or 'practical wisdom'.

Teachers' action research in the context of a Stenhousian 'process model' of curriculum design can be depicted as a form of 'practical philosophy' in the Aristotelian sense, where the aims of education are clarified in the process of determining the means of realising them in particular contexts of action. In so arguing I was attempting to locate and anchor Stenhouse's ideas in a philosophical view of the relationship between thought and action which he did not explicitly acknowledge and fully articulate. However, he did claim that his Humanities Project was the first curriculum project to be grounded in the philosophy of education (no doubt acknowledging the influence of R.S. Peters).

In linking the concept of phronesis to action research I had hoped to illuminate aspects of Stenhouse's concept of 'teacher research', in order to clarify its distinctiveness as a form of action research to one shaped by the logic of technical rationality. Carr (2006 p.424) views this attempt to locate Stenhouse's concept of 'teacher research' with Aristotle's notion of 'practical philosophy' as part of a revised idea of action research, transcending that of Lewin and his followers, who had "construed action as little more than a practical skill or technique to be assessed in terms of its instrumental effectiveness." Stenhouse had mounted a powerful critique of the use of an objectives model of curriculum design; an example of the encroachment of technical rationality (techne) into thinking about education. I argued that his contrast between the two forms of 'practical' reasoning, which underpinned the 'process' and 'objectives' models, had been around a long time. In Ethics Aristotle contrasted activities that involved the making of products with those that consisted of doing something well. Technical rationality is a mode of 
reasoning that is appropriate for making activities while phronesis is the mode that is appropriate for doing things well. For Aristotle, as Carr (2006 p.246) argues, phronesis can only be acquired by practitioners, who "in seeking to achieve the standards of excellence inherent in their practice, develop the capacity to make wise and prudent judgements."

One of the things I wanted to bring out as an implication of Stenhouse's concept of 'teacher research' was that teaching is an ethical practice, rather than simply a making activity. From this perspective teacher research is appropriately understood as a form of phronesis, which consists of a quest for virtue in action (see Hughes 2001 p.105). A critical feature of an ethical practice (praxis) from an Aristotelian point of view is that the actions of which it consists are seen by the agent as an expression of the values to which they are committed, in contrast to the skills and techniques that make up a making activity. Skills and techniques are assessed in terms of the outcomes of activities, whereas virtues are assessed in terms of the habitual dispositions of the agent to make emotional responses to a situation that are consistent with their values (see Hughes 2001 pp. 54-56, p. 58). For Aristotle virtues are not simply inclinations to pursue certain moral ends. They also, as Hughes has argued (p.107), constitute understandings of what is required in particular circumstances and "it is the action that embodies that understanding which now becomes the content of our virtuous inclination." Hence, Aristotle's conception of phronesis as a quest for virtue and the significance of the link I tried to establish between this account of practical reasoning and Stenhouse's Process Model of curriculum design and his idea of the 'teacher as a researcher'.

Some might argue that there is a tension between Stenhouses's Process Model and seeing teacher research in this framework as a form of phronesis. The Process Model requires the ends of action to be analysed into their procedural implications in the form of procedural principles. Hughes (pp. 118) believes it is clear that Aristotle held a version of what is now called 'virtue ethics', one version of which reads as follows:

"The best way to know what one should do is to think of how to behave virtuously, rather than thinking of how to follow a moral principle."

Hughes argues that Aristotle undeniably spends more time "talking about virtues than he does about moral principles." He regards the latter as lacking the exactitude of geometry or physics, inasmuch as they cannot prescribe exactly what is required. However, Hughes claims (pp.219220), this does not mean that Aristotle is in favour of a virtue ethics and 
"has little interest in moral principles". The latter can orientate practical reason in the quest for virtue. For Aristotle practical wisdom "involves a grasp of both moral principles and individual situations" and virtues "are defined in terms of the responses which facilitate such a grasp, and motivate actions in which that grasp is expressed" (Hughes p. 220). This point of view chimes very well with Stenhouse's view of the relationship between pedagogical procedural principles and teachers' research in particular contexts of action.

The attempt outlined above, to conceptualise teachers' research as a form of phronesis concerned with the quest for virtue in teaching, explains Carr's and my own critique of those who depict educational action research in Lewinian terms - as a methodology for assessing the practical utility of social science theories, rather than a practical philosophy that is concerned with the development of practical knowledge to guide virtuous action. Reviewed and revised in these terms Carr (2006) sees Lewin's action research cycle being transformed from a method, by which practitioners apply social science theories to their practice, into a mode of inquiry that allowed them to test the adequacy of their own 'tacit theories'. As such, he writes (p. 434),

"... it would be a mode of inquiry whose chief task was to reclaim the sphere of praxis from its modern assimilation to the sphere of techne by fostering the kind of dialogical communities in which open conversation can be protected from the domination of a research methodology." (see also Elliott 2007b pp. 149-165).

Carr claims that this is no easy task to achieve within the dominant culture of modernity. However, he argues that it is important to persist with this mode of inquiry by seeking "to ensure that the void created by the demise of practical philosophy will not be filled by a research methodology that will make it impossible for action research to defend the integrity of praxis against all those cultural tendencies that now undermine and degrade it" (p.434).

In the next section I will provide some examples of ethical frameworks that conform to the 'process model', and the kind of teacher engagement in research they require in order to transform curriculum aims and principles into virtuous forms of action. In doing so I shall argue that what they all share in common is a conception of 'understanding' as a pedagogical aim that is broadly ethical in character, and which cannot be broken down into pre-specifications of learning outcomes. 


\section{Action research as a form of ethical inquiry}

As argued above, in the process of action research curriculum aims and principles (values) become articulated as objects of reflection in parallel with the means of realizing them in action. Teachers not only change their teaching strategies but also clarify their curriculum aims and values. For example, teachers have undertaken action research to create conditions for students to engage in more 'self-directed' or 'autonomous learning'. In reflecting about their strategies for realizing this aim they have inevitably called into question the way they have construed the aim itself. Initially 'autonomous learning' may be construed as an individualised process, but as teachers reflect about the actions they take to realize this aim they tend to move towards a more social view of the process; one in which autonomy is fostered through opportunities to engage in free and open discussion with the teacher and other pupils. Hence, action research is a kind of practical philosophy of education that opens up a space in classrooms for ethically committed action (praxis).

Curriculum aims and principles specify pedagogical criteria for representing curriculum content - the objects of learning - to students in an educationally worthwhile manner. To get clearer about them through action research is to get clearer about the ideal pedagogical relationship between the content of the curriculum, teachers and learners. This explains why teachers' action research has tended to emerge in curriculum change contexts that require content to be represented as dynamic objects of the student's understanding - of his/her thinking and discernment - rather than simply as inert 'knowledge' to be learned, remembered and applied. Lo (2012 pp. 41-43) has recently echoed Lawrence Stenhouse when she argues that an object of learning "is different from a learning objective." By stating the learning objectives teachers are "treating the end result of learning as if it can be predetermined", she claims. By way of contrast an object of learning is a dynamic concept. Lo writes:

"Through the course of teaching and interacting with their students, teachers gain a better understanding of the object of learning; teachers regularly make adjustments to it." (p.51)

Her words echo Lawrence Stenhouse's contention that there can be "no curriculum development without teacher development" and his idea of 'the teacher as a researcher' (see Stenhouse 1975, pp.142-165). Remove teachers'-based action research from such a curriculum change context, I 
would argue, and you cast it as a technical mode of inquiry (techne) as opposed to an ethical mode (phronesis). What follows are some examples of ethical frameworks that are designed to support a process of 'teaching for understanding' in the context of a process model of curriculum development. I outline first some earlier work, followed by more recent contributions.

\section{Stenhouse's 'The Humanities Curriculum Project' (HCP)}

Stenhouse (1975 Ch.'s 5-7) evolved a 'process model' of curriculum design for The Humanities Curriculum Project on the grounds that an 'objectives model' was inappropriate as an expression of its aim.

"The pedagogical ... aim of the project is to develop an understanding of social situations and human acts and of the controversial value issues which they raise" (p. 93).

He argued (p.94) that two implications of this aim were worth pointing out:

"First, it is implied that both students and teachers develop understanding, that is, the teacher is cast in the role of a learner. Second, understanding is chosen as an aim because it cannot be achieved. Understanding can always be deepened. Moreover, there must always be dispute as to what constitutes a valid understanding. The teacher and the group have to accept as part of their task an exploration of the nature of understanding."

Rather than specifying measurable outputs of learning a number of principles of procedure were logically derived from the aim.

HCP's Principles of Procedure were as follows:

1. That controversial issues should be taught in the classroom with adolescents;

2. That teachers should not use their authority as teachers as a platform for promoting their own views;

3. That the mode of enquiry in controversial areas should have discussion rather than instruction at its core;

4. That the discussion should protect divergence of view among participants;

5. That the teacher as Chairperson of the discussion should have responsibility for quality and standards in learning. 
(The Humanities Project: An Introduction, p.8)

These principles then provided foci for teachers' research. From evidence gathered with teachers in the project's 'trial schools' a number of action patterns were identified in the light of these principles as either consistent or inconsistent with the aim. These were initially formulated as general hypotheses for other teachers to test in their own classrooms. However, Stenhouse was concerned that they would be treated as prescriptive rules rather than hypotheses, so they were cast in the form of questions for reflection within the project's self-training procedure for teachers. Some extracts from this procedure are as follows:

$>$ To what extent do you interrupt students when they are speaking? Why and to what effect?

Reflective discussion can often be slow-paced and contain sustained silences. What proportion of these silences are interrupted by you? ... the students can use silence as a weapon to make the teacher take over the task they should face as a group.

$>$ Do you press towards consensus? For example, "Do we all agree?" If so what is the effect of this type of question? Compare this with the effect of: "What do other people think?" "Does anyone disagree with that?" "Can anyone see another possible view or interpretation?"

$>$ To what extent do you confirm? Do you, for example, say "Yes" or "No" or "An interesting point" or "Well done" or "That's interesting"? What is the effect of this on the group? ...

- Are you neutral on controversial issues? ... Are values implicit in the questions you ask? Are they implied in the words, gestures, or tone of voice with which you follow a student's statement? Are you careful to maintain balance in clarifying or summarising a position or point of view? Are you scrupulous not to feed into the discussion evidence intended to push the group towards a view you yourself hold? Do you draw attention by questions to certain parts or aspects of a piece of evidence which seems to support a viewpoint with which you agree?

(The Humanities Project: An Introduction, pp. 30-32)

Bruner's 'Man: A Course of Study' (MACOS).

Stenhouse did not confine the use of the 'process model' to areas of the curriculum where value issues clearly constituted the main objects of learning. He felt that it was also appropriate to all those areas where the contents to be learned were best conceived as objects of understanding. In 
this respect he was particularly attracted by Jerome Bruner's influence on the design of a behavioural science and anthropology curriculum for Junior High School pupils in the USA, entitled Man: A Course of Study. The design conformed to Bruner's idea of a 'spiral curriculum', in which children deepened their understanding of the core concepts of a discipline by continuing to spiral back into exploring their meaning through the study of increasingly complex content. The curriculum framework of MACOS consisted of key concepts in the behavioural and anthropological sciences, such as 'life cycle', 'nurturing', 'innate and learned behaviour', 'structure and function', 'natural selection' and 'mythology'. The content consisted of case studies of the behaviour the Pacific Salmon, Herring Gull, Baboon and the Netsilik Eskimo. Children were expected to explore this content in the light of one or more of the key concepts. Stenhouse points out that the method of study is comparative, inasmuch as the pupils are expected to make running comparisons with their own society and experience (see Stenhouse 1975 p 90). He cites Bruner's summation of the content of the course and the key questions to be addressed through studying it:

"The content of the course is man [sic]: his nature as a species, the forces that shaped and continue to shape his humanity. Three questions recur throughout:

What is human about human beings?

How did they get that way?

How can they be made more so?"

(Bruner 1966, p.74).

Stenhouse claims that:

"These questions invite teacher and students to speculate about humanness in the broadest sense as they study the materials of the course". (Stenhouse, 1975 p. 91).

He points out that MACOS is not a curriculum designed on a prespecification of behavioural objectives. Rather the teaching goals, defined for the course by its designers, explicitly "centre around the process of learning rather than its product." These are:

1.To initiate and develop in youngsters a process of question-posing (the inquiry method);

2.To teach a research methodology where children can look for information to answer questions they have raised and use the framework 
developed in the course (e.g. the concept of the Lifecycle) and apply it to new areas;

3. To help youngsters develop the ability to use a variety of first-hand sources as evidence from which to develop hypotheses and draw conclusions;

4. To conduct classroom discussions in which youngsters learn to listen to others as well as to express their own views;

5. To legitimize the search by giving sanction and support to open-ended discussions where definitive answers to many questions are not found;

6. To encourage children to reflect on their own experiences;

7. To create a new role for the teacher, in which he becomes a resource rather than an authority.

(see Hanley, Whitla, Moo, Walter 1970, 5)

Stenhouse argues (1975 p.92) that these goals are in fact what he depicts as principles of procedure. Unfortunately, these principles were not translated into concrete action strategies by engaging teachers that used the curriculum in a systematic process of action research. Whilst providing an excellent example of a process model of curriculum design, MACOS perhaps took teachers' ability to translate these principles into concrete actions in their particular teaching contexts too much for granted. Teacher research was not part of the MACOS implementation strategy, as it was in HCP. However, for Stenhouse, the design of MACOS demonstrated the potential of the process model of curriculum planning, as an alternative to the behavioural objectives model, across curricula based on the disciplines of knowledge. Given his dynamic view of the nature of knowledge a 'process model' of curriculum planning seemed more appropriate than an 'objectives model'.

Stenhouse viewed all propositional knowledge as provisional and therefore open to question. Propositions were open to challenge in the light of evidence and therefore objects for thinking and discussion. The main concepts and ideas embedded in the disciplines, for Stenhouse, were resources for thinking about experience rather than objects with definitive meanings to be mastered. He regarded 'the development of different forms of understanding' as a central aim of education, but an open-ended process that is always capable of development in depth, and in relation to which what constitutes a valid understanding is always open to question. Stenhouse (1975, pp.70-83) argued that planning by objectives distorted the nature of knowledge across the curriculum disciplines, although he believed that it was appropriate for the teaching of specific technical skills. 
Elliott and Adelman's 'Ford Teaching Project' (Ford T).

The school-based curriculum reform movement in the UK in the 1960s and 1970s generally espoused 'inquiry/discovery learning' as a pedagogical aim, but the projects generally revealed a considerable gap between aspiration and practice. It was too easily assumed that teachers were capable of translating innovatory pedagogical goals into practice without support. Elliott and Adelman's Ford T Project brought teachers together across the curriculum disciplines and age levels to explore the possibility of constructing a general pedagogy of 'inquiry/discovery learning' through action research (see Elliott 2007 Ch.2 esp. pp. 41-42 and pp.50-55).

The core pedagogical aim of inquiry/discovery learning was defined in terms of independent or self-directed thinking. This aim was then analysed into four basic freedoms for students. The following formulation represents the outcome of discussions with the teachers:

(1) To identify and initiate problems for inquiry;

(2) To express their own ideas and develop lines of inquiry;

(3) To discuss problems, ideas and evidence;

(4) To test hypotheses and evaluate evidence.

The pedagogical implications of the four freedoms of inquiry/discovery learning were then specified as a set of negative and positive procedural principles for orientating the role of teachers. The negative principles emphasize the teacher's responsibility to refrain from actions that impose constraints on students exercising these freedoms, with a reminder also to do all in their power to protect students from other forms of external constraint. The positive principles emphasize the teacher's responsibility to intervene in the learning process in ways that actually enhance students' capabilities to exercise the freedoms. Implicit in the procedural principles of the project is a distinction between the negative and positive aspects of freedom. Students, for example, may be free from external constraints on their freedom to express their own ideas and develop them into hypotheses but still be unable to exercise this freedom because they lack the necessary capabilities.

This clarification of the aims and principles of inquiry/discovery teaching was subsequently used by Ford $\mathrm{T}$ teachers as a framework for gathering and analyzing data about the problems of engaging students in inquiry/discovery learning and testing strategies to ameliorate them. In the light of it they were able to identify the extent to which their teaching 
strategies constrained or facilitated such learning, and to compare and contrast their experience across a range and variety of classroom, school and curriculum contexts. Over time they were able to discern certain universal patterns of interaction in each other's classrooms that were problematic for the realization of their pedagogical aim, and begin to experiment with strategies for changing them in discussion with each other.

Representing findings, two examples:

\section{Example 1}

2. The freedom to express ideas and develop lines of inquiry. Procedural Principles

(a) Refrain from preventing students expressing their own ideas and developing lines of inquiry.

(b) Help students to develop their own ideas and lines of inquiry.

Constraint

\subsection{Subject-Centred Focusing}

When the teacher's questions focus students' attention solely on the subject-matter, rather than on their own ideas about it, s(he) may prevent them from initiating or developing their own ideas. Such focusing will be interpreted as an attempt to find out whether they know what s(he) expects them to know.

\section{Constraint Removing Strategy}

Refrain from framing your questions in terms which draw attention exclusively to the subject-matter rather than students' thoughts about it.

\section{Guidance Strategy}

Ask person-centered questions which focus the students' attention on their own ideas with respect to the subject-matter.

\section{Example 2}

3. The freedom to discuss problems, ideas and evidence. Procedural Principles

Refrain from restricting students' access to discussion.

Help pupils to learn how to discuss.

\section{Constraint}

\subsection{Reinforcing ideas}

When the teacher responds to students' ideas with utterances like 'good', 'yes', 'interesting' etc. s(he) may prevent others from expressing alternative ideas. Such utterances may be interpreted as rewards for providing the responses required by the teacher.

\section{Constraint Removing Strategy}


Refrain from utterances that might imply finality e.g. 'yes', 'good', 'right'.

\section{Guidance Strategy}

Reward students for their contributions to discussion by listening carefully to their remarks and asking others to do so.

(Ford Teaching Project, Unit 3 Hypotheses, Implementing the Principles of Inquiry/Discovery Teaching, Centre for Applied Research in Education, UEA, Norwich. http://professorjohnelliott.wordpress.com/pp. 1-51)

The idea behind the construction of such a knowledge base was to provide other teachers, who embraced a similar pedagogical aim, with a set of diagnostic and action-hypotheses to examine, test, refine and further develop in relation to their own pedagogical practices. Hence, it was hoped that other teachers might avoid constantly 'reinventing the wheel', while having space for exercising personal judgments in an ongoing process of collaborative professional knowledge construction.

All the above examples (with the exception of MACOS) depict educational action research projects that were designed and operated in the 1970s within the context of school-based curriculum reforms. The question that now arises is whether there are contemporary examples of educational action research that, in the words of Carr, appear to be successfully resisting the assimilation of praxis to techne in sustainable ways and opening up spaces for the quest for virtue in teaching. If so, which aspects do they share in common with the examples I selected as paradigmatic, and have not, in the words of Carr, "been filled with a research methodology" that makes it impossible for them to defend the integrity of praxis? With this possibility in mind I looked at accounts of educational action research published in six issues of the Educational Action Research Journal during 2013-14. What follows is a summary of my somewhat impressionistic reading, that is certainly open to challenge and discussion from readers.

First, I found a number of accounts of educational action research that specified pedagogical aims, which referred to qualitative dimensions of the learning process, and viewed teaching as an ethical practice (see, for example, Forman-Peck \& Travers 2013, pp.28-41; Mockler 2014, pp. 146-157; Casey 2013, pp.147-163; Goh \& Loh 2013, pp202-217).

However, in some of these accounts there was relatively little systematic reflection about such aims, and attempts to clarify their ethical implications in the form of procedural principles were few. The focus of 
reflection tended to be on the means as opposed to means and ends jointly. There was little evidence in the articles I looked at where in the process of action research teachers developed their conception of educational aims in the process of reflecting about the means of achieving them. Aims tended to be treated as fixed ends. Such action research might be depicted as a quest for virtuous action but is rather limited as a dynamic process of practical philosophy in which ends and means are treated as joint objects of reflection.

Second, a number of articles focused on action research processes and procedures rather than student learning (see Ado 2013 pp.131-146; Arhar, Niesz, Brossmann, Keebley, O’Brien, Lee \& Black 2013 pp.218-236). Since some of these articles tended to be written by academic facilitators, such as teacher educators and educational researchers, they might be regarded as 'second-order' accounts of action research, where the focus is on the development and learning of the teachers and other participants involved, rather than on the learning of the students. In this respect learning tends to be understood as a process of inquiry involving the collaborative and democratic construction of insights, shared understandings, and practical knowledge within 'communities of practice'. Some of the articles misleadingly depicted social processes of action research as methodologies, suggesting that academic participants and facilitators are under pressure to justify their involvement with action research in methodological terms. (However, see Locke, Alcorn, and O'Neill pp. 107-123). The danger here is that the processes concerned get represented as fixed ends of teacher professional development and learning that are not open to critical reflection. The second-order action research process thereby reduces the space for virtuous action by focusing exclusively on the methods and devices employed as means.

Third, I found only a few articles that systematically set out the findings of the action research they described, in a form which could be tested by other practitioners. There was little attempt to explore the generalizability of any findings across different contexts of action. Many articles consisted of case studies of action research within a particular context. The assumption underpinning them seems to be that action research, as the study of action in particular circumstances, cannot yield universal insights that are useful for other practitioners to explore in their particular contexts of action.

Fourth, I could find only one account of teachers' action research that is informed by an explicit learning theory and designed to test and develop the use of that theory as a pedagogical tool (see Tan 2014 pp. 427-411). 
Fifth, there were a number of articles that theorised about the nature and form of action research. They provide a theoretical resource for resisting the transformation of educational action research into a form of technical rationality (see Hammond 2013 pp.603-670; Gibbs 2014 pp. 428-440; Gale, Turner and McKenzie pp.549-564).

I must conclude that the potential of educational action research to resist the encroachment of technical rationality into the field of education is currently rather restricted. Although there is considerable evidence of global spread and a sharing of aspects that tend to support the integrity of praxis as a space for virtuous action, educational action research shapes up in ways that are limited in this respect. The creation of sustainable spaces for virtuous action will need to be supported by the systematic presentation of findings across different action contexts, in the form of practical hypotheses to test, and the use of learning theory to inform the quest for virtuous action through action research. It is to these matters that I now turn.

Teachers' action research and the issue of generalizability

Some may argue that what I have called 'action research' is best described as 'action inquiry' or 'reflective teaching'. I have always persisted with the use of the term 'action research' because research places teachers under an obligation to render the insights they have gained from an inquiry in some publicly accessible form. This is important, because teachers need to build a stock of common knowledge about how to realise their educational aims and values in practice, in order to enhance their claim to be a profession. Hence, any insights that have been generated by individuals and groups of teachers through this kind of inquiry need to be made accessible to other teachers as hypotheses for them to test and explore in their own classroom settings. The hypotheses cited above, with respect to both the HCP and Fort T projects, constituted an attempt to render the insights from teachers' action research so accessible.

It is often argued that case studies of teachers' attempts to bring about change in their particular contexts of action are not generalizable. Those who argue this have a particular view of generalisation in mind. They assume that generalisation depends on statistical aggregation. However, there are other uses of the term. We can generalise across cases by comparing and contrasting them in a way that highlights similarities in many of their practically relevant features. This is what some groups of teachers do, when they carry out action research together into how to 
realise in their particular action settings the educational aims and values they share in common. By comparing and discussing each other's case data and case studies they develop shared insights into the practically relevant features of the situations that arise in their teaching. These shared understandings can then be reported by the action research group to other members of the teaching profession and grounded in evidence drawn from across their case studies. Even a single case study may have generalising potential inasmuch as teachers reading it may discern practically relevant features that illuminate their own practical situations. Educational action research aims to contribute to the teaching profession's stock of pedagogical knowledge. It should not be viewed as a process of private 'navel gazing' or personal 'therapy'. To do so would effectively hand control over what is to count as public knowledge about the practice of teachers in educational institutions to external researchers or policy makers. The development of teaching as a form of virtuous action depends on the development of a pedagogical science, in which teachers play a central role as researchers.

The role of theory in the development of teaching as a form of virtuous action

Lawrence Stenhouse gave 'theorising' an important role in the development of teaching as a form of action research. He acknowledged that individual teacher researchers will be primarily concerned to better understand their own classrooms rather than generalising beyond their experience. However, in this context he argued that the primary role of theory is to systematically structure a teacher's understanding of his or her work in a particular context (1975 p.157). This role is important because teachers' self-understanding depends on the quality of their communication with other teachers. For Stenhouse the problem of generalizability was not so much epistemological as psychological and social. Teacher research required the adoption of a self-critical stance and a willingness to submit their own work to the scrutiny of others. It presupposed a 'professional community of practice' rather than an activity of lone individuals. Stenhouse argued (1975, p. 157) that in order for teachers to capture and express their emerging insights to each other they needed to develop a common vocabulary of concepts and a syntax of theory. Such a theoretical framework should be testable by teachers and open to the development of new concepts and theory.

Stenhouse claimed that action research informed by theory made it possible to synthesise teachers' case studies as a source of pedagogical insights that can be cast in propositional form, albeit open to revision in the light of an accumulating repertoire of cases (1975 p.157). He believed 
that such conditions could be achieved "through a mutually supportive co-operative research in which teachers and full-time research teams work together (p.159)". Although professional groups of teachers should work together to construct pedagogical knowledge this should not exclude co-operation with professional researchers and curriculum specialists.

There is an issue about whether the Aristotelian concept of phronesis or 'practical wisdom' can accommodate the idea of 'theory-informed ethical inquiry'. Carr (2004, pp. 61-62) has argued, contrary to my view, that Aristotle's concept of phronesis does not name a reasoned state of ethical judgment, but rather a process grounded in taken-for-granted beliefs that are embodied in a practical tradition. He contends that phronesis is not always sufficient to determine good practice in some situations. Problems arise that cannot be resolved on the basis of traditional understandings of good practice. They challenge practitioners to call these existing understandings into question in order to discern new ways of expressing the values or ends that are inherent in the tradition. Carr points out that thinking of this kind is the process by which established ethical knowledge gets reconceived to develop the tradition. It will entail a rigorous examination of the biases (pre-understandings, even prejudices) about good practice that practitioners bring to their situation, and a systematic gathering of evidence around the problem(s) it presents. Carr concludes that although this form of ethical reasoning depends on phronesis it reflexively transcends it. I am inclined to persist with my interpretation of the concept of phronesis, and in this respect draw support from Joseph Dunne's meticulous scholarship on Aristotle's concepts of practical knowledge (see 1993, p. 244). He cites textual evidence that makes it clear that phronesis picks out a rational capacity for ethical action.

In 1978 I made a distinction between educational research, aimed at the realization of educational values, and research on education. I depicted the former as a form of commonsense theorising (see Elliott 2007 Ch. 5, especially pp. 95-98). In this respect it differed significantly from Aristotle's view of practical ethical reasoning as non-theoretical. Theoretical knowledge (episteme) for Aristotle was quite distinct from practical wisdom and reasoning. As Dunne points out, for Aristotle the spheres of theory and practice are incommensurable, the former being 'emphatically distinguished from any knowledge that might have practical import' (Dunne, 1993, p. 
238). Theoretical knowledge consisted of a contemplative grasp of the principles that governed an unchanging and eternal cosmic order transcending the contingencies of everyday living.

I wished to see the term 'theory' freed from essentialist assumptions-assumptions based on the nature of the world, or the human mind or language that shaped its meaning in Greek thoughtand put to the service of praxis (see Elliott 2009 pp.28-38). Concepts should rather be seen as characterising value-laden conceptions of ends. They constitute concrete universals inasmuch as their meaning can only be determined through concrete practical experience. Moreover, their meaning changes over time and with experience.

The process of continuously constructing and reconstructing the meaning of our value concepts in practice can usefully be depicted as a form of commonsense theorising, in which case educational theories are generated in the context of practice through the judgments and actions of teachers. This provides a very different picture of educational theory from the one that has come to dominate relationships between academics and the teaching profession. It opens up new possibilities of engaging teachers with educational research.

An excellent example of theory-informed teacher research is provided by the work of Lo Mun Ling and her co-workers in Hong Kong, in the context of the curriculum reforms initiated by the Hong Kong Curriculum Development Council in 2000, entitled 'Life-long Learning and Whole-person Development.' The curriculum framework created spaces for school-based action research and the HK government established five projects to help teachers develop strategies for implementing different aspects of the framework. One of these was to explore the potential of 'variation theory' to help teachers deal with increasing pupil diversity in their classrooms as an outcome of the reforms (see Lo, Pong, \& Packey (Eds.), 2005). This phenomenographic theory of learning was developed through a series of 'design experiments' in Swedish schools by Marton and Booth (1997) and their co-workers. In 1998, under the leadership of Marton, then working in Hong Kong as a visiting scholar, Lo Mun Ling participated in a study that used 'variation theory' as an explanatory framework to account for why some teachers are more effective than others in bringing learning about for their students. The theory 
focuses on the object of learning and is interested in students' ways of experiencing and understanding it. The study found that the theory helped to explain why some teaching acts did or did not help students to learn effectively, and that this was related to the kinds of patterns of variation teachers enacted in their classrooms to relate their students to the object of learning (see Lo 2012, Preface). As a result Lo and colleagues created a model of action research based on Japanese Lesson Study method (see Lewis, C. Perry, R and Friedkin, S, 2009) to help teachers to collaboratively explore the pedagogical potential of 'variation theory' for designing their lessons and developing their teaching. They called this theory-informed model of action research Learning Study (Lo 2012 pp. 9-39) and embarked on a series of such projects, the first of which, on pupil diversity, was briefly depicted above. Through these teachers'- based action research projects 'variation theory' was further articulated, refined and developed in Hong Kong (see Lo and Marton 2012 pp.7-22) e.g.

The direct and indirect objects of learning., The differences between the intended, enacted and lived object of learning., The distinction between critical aspects and critical features of the object of learning.,

The different kinds of variation in relation to the process of Learning Study; with respect to learners, teachers, and teaching strategies.

(see Lo 2012 pp. 41-102).

'Variation theory' may be depicted as a theory about the pedagogical conditions under which understandings of objects of learning are developed. Lo (2013, pp.302-303) has commented on commonalities she perceives between the theory and practice of learning study and Stenhouse's idea of 'the teacher as researcher'. First, the object of learning must be judged to be educationally worthwhile on the grounds that it is of enduring human interest because of its importance to the human situation. Second, the object of learning is dynamic. Knowledge of it is always provisional and open to question. Its critical features cannot be predetermined in advance but are dependent on the students' ways of seeing, and what is judged to be critical for advancing their existing understanding in greater depth. In this respect Stenhouse's 'process model' of lesson design strongly resonates with 'variation theory'. Third, knowledge cannot be taught 
if it is abstracted from the research process by which it is created. Such abstraction distorts the nature of knowledge. Therefore all teaching should be research or inquiry based. Fourth, theories of learning about the relationship between the learner, the object of learning, and the teacher - such as 'variation theory' - need to be field tested by teachers in their classrooms. Such theories provide a shared language for teachers to reflect about and discuss their practice together. In the process teachers both generate knowledge of how to put a theory into practice and also test and refine the theory itself. Fifth, school-based curriculum development is a process of testing a series of theory-informed educational experiments in classrooms by teachers.

Variation theory may be understood as a conceptual framework that informs action research into the development of 'teaching for understanding.' I would argue that 'variation theory' is consistent with Stenhouse's process model of curriculum design because it construes teaching for understanding as an ethical conception of the ideal relation between the learner as a person, the object of learning and the teacher. As such the relationship of 'variation theory' to the pedagogical aims and principles that define a process model of curriculum design deserves further exploration. For the moment it is sufficient to argue that 'the transformation of teaching into a form of virtuous action' cannot be separated from the testing and development of educational theory through teachers' research. They go together.

\section{Action research integrates teaching and research}

Many teachers say they are too busy teaching to do research. This is because they have learned to view all research as a mode of knowledge production that is external to their practice as teachers. They have often been told in their training that their role is to apply the findings of research to their practice. Having failed to discern the relevance to their practice of findings from externally conducted educational research, many teachers will interpret research as a proposal to give them more responsibility for research in order to enhance its application to their practice. On the basis of such an interpretation teachers will inevitably resist what they perceive to be an additional work-load, when they already feel overloaded and stressed by having to comply with the quality assurance mechanisms being put into place to render them more publicly accountable for their teaching. 
Such resistance is based on a misunderstanding of teacher research. It is not simply 'insider research' but research that is an integral part of teaching rather than a separate process. The findings from such research are not retrospectively applied to teaching but developed in the context of teachers' actions to bring about an educationally worthwhile teaching and learning process. Just as research is an integral part of teaching so teaching becomes an integral part of research.

Of course this kind of research-based teaching will be more timeconsuming than the traditional practice of teaching. The latter will appear to be less time consuming because it is largely grounded in taken-forgranted knowledge that is handed down to teachers as part of their induction into 'the practical realities' of teaching in classrooms and schools. Traditional teaching is largely based on tacit craft knowledge, which enables the teacher to make quick intuitive judgements about what to do in a given situation. However, the rapid pace of social and economic change in society has meant that traditional teaching may no longer work as the practice of virtue, which enables teachers to handle wisely on a day-to-day basis those contingencies that arise in formal learning contexts. These contingencies call for a more self-reflexive mode of teaching, in which traditional understandings of situations are called into question and new understandings evolved as a basis for the practice of virtue in teaching. 'Action research' is the name we give to this kind of teaching. Its importance resides in helping teachers to reconstruct together their professional tradition and the culture of teaching and learning. It does indeed take more time than teaching that is largely grounded in taken-for-granted knowledge. It involves creating spaces for teachers to reflect individually, together and with their students (and also with other stake-holders such as parents) about the problems that arise in the contexts of their practice. And it also involves creating space for gathering evidence from different points of view other than the teacher's own, such as those of their students and professional peers, which will serve to discipline post-lesson analytic conversations and reflections. This triangulation data may include observational evidence gathered by the teacher's peers or a collaborating researcher from a local university, or evidence gathered from their students in the form of interviews and opinion surveys. "No time to do research" implies "no time to develop my teaching in any fundamental sense."

Elliott and Yu evaluated the feasibility and impact of Lo's 'Variation for the Improvement of Teaching and Learning' (VITAL) Project' that was funded by the Hong Kong government. They concluded (see Elliott and Yu 2013) that in spite of the resource intensive nature of Learning Study 
it had a long-term and sustainable impact on the classroom practice of many teachers, who were able to make use of 'variation theory' to inform their action research.

Action research should no longer be an optional extra for teachers. There are fewer comfort zones into which they can retreat from the problems they are confronted with in formal educational settings. They can either strive to empower themselves to make and create worthwhile educational change through action research, or simply hand responsibility for change over to policy makers and educational managers. The latter are attempting in many countries to re-engineer the educational system to render its outcomes more predictable. In this scenario teachers are cast in the role of technical functionaries responsible for delivering changes that have been planned and designed beyond the world of the classroom and the school. In effect it is a scenario that disempowers and deprofessionalises teachers as agents of educational change. It is also one in which the purposes of education are not open to reflection. This is left to market forces to decide. Teachers will not be expected to safeguard students' access to 'goods' that are specifically educational and refer to learning in both its achievement and process aspects. For example, teachers may aim to promote 'self-directed learning' in their classrooms as an educational good. But this implies certain process values, such as teaching in a way that does not foster dependence on the teacher for knowledge and ideas, or giving pupils the freedom to express and develop their own ideas, or respecting the right of pupils to think critically about the subject-matter. The educational aims of teachers cannot simply be regarded as contingently related outcomes of the teaching and learning process. This is because they also imply what is to count as an educationally worthwhile process of teaching and learning, and in doing so view teaching as the practice of virtue in education.

\section{A concluding note}

Educational action research as I have depicted it above is not lacking in scientific rigour as some have also argued. It demands, like all science, the exercise of what John Dewey called the 'democratic virtues'; namely, curiosity, honesty and integrity, open-mindedness, and respect for freedom of thought and discussion. It is shaped by a democratic as opposed to a technical rationality (Elliott 2007 pp. 149-165), embodied as I hope to have illustrated in the 'process model' of curriculum planning and informed by an appropriate pedagogical theory.

\section{References}


Ado, K (2013), 'Action Research: professional development to help support and sustain early career teachers', Educational Action Research Journal, vol. 21, No. 2.

Arhar, J., Niesz, T., Brossmann, J. , Koebley, S., O’Brien, K., Loe, D., and Black, F (2013), "Creating a "third space" in the context of a university-school partnership: supporting teacher action research and the research preparation of doctoral students', Educational Action Research Journal,Vol. 21, No. 2.

Aristotle (1998) Nicomachean Ethics, Oxford \& New York: Oxford

Bruner, J, S. (1966) Towards a Theory of Instruction, Cambridge, Mass: The Belknap Press of Harvard University Press.

Carr, W (2004), 'Philosophy and Education', Journal of Philosophy of Education, Vol. 38, Issue 1.

Carr, W (2006) Philosophy, Methodology and Action Research, Journal of Philosophy of Education, Vol. 40, Issue, 4.

Casey, A (2013) “ "Seeing the trees not just the wood": steps and not just journeys in teacher action research', Educational Action Research Journal, Vol. 21, No. 2.

Dunne. J (1993) Back to the Rough Ground: practical judgement and the lure of technique, Notre Dame, Indiana: University of Notre Dame Press.

Elliott. J (1991) Action Research for Educational Change, Milton Keynes \& Philadelphia: Open University Press.

Elliott, J (2007a) Reflecting Where The Action Is - The selected works of JOHN ELLIOTT. London \& New York: Routledge. Ch. 2. \& Ch.5.

Elliott, J (2007b) 'Educational Research as a Form of Democratic Rationality' in Bridges, D and Smith, (Eds.) Philosophy, Methodology and Action Research, Oxford: Blackwell.

Elliott, J (2009) 'Building Educational Theory through Action Research' in Somekh, B and Noffke, S (Eds) The SAGE handbook of Educational Action Research, Thousand Oaks (Calif), London, New Delhi, Singapore: Sage Publications. 
Elliott, J \& Yu, C (2013) Learning Studies in Hong Kong Schools: A Summary Evaluation Report on the 'Variation for the Improvement of Teaching and Learning ' (VITAL) Project, Education \& Didactique, Vol.7 No.2.

Ford Teaching Project, Unit 3 Hypotheses, Implementing the Principles of Inquiry/DiscoveryTeaching, Centre for Applied Research in Education, UEA, Norwich. http://professorjohnelliott.wordpress.com/

Gale, k., Turner, B and McKenzie, L (2013) 'Action research, becoming and the assemblage: a Deleuzian reconceptualization of professional practice', Educational Action Research Journal, Vol. 21, No. 4.

Gibbs, P. (2014), 'Deliberation, capability and action research: knowledge and becoming', Educational Action research Journal, Vol. 22, No. 3.

Goh, L.H and Loh, K-C (2013) “ "Let them Fish": empowering studentteachers for professional development through the project approach', Educational Action Research, Vol. 21, No. 2.

Hammond, M (2013), 'The contribution of pragmatism to understanding educational action research: value and consequences', Educational Action Research Journal, V ol. 21, No. 4.

Hanley, J. P., Whitla, D.K., Moo, E.W and Walter, A.S. (1970) Curiosity, Competence, Community: Man: a course of study, An Evaluation. 2 vols. Cambridge, Mass: Educational Development Center, Inc.

Hughes, G.J (2001) Aristotle on Ethics, London \& New York:Routledge.

Lewis, C. Perry, R and Friedkin, S (2009) Lesson Study as Action Research in Noffke, S and Somekh, B (Eds.) The Sage Handbook of Educational Action Research, Los Angeles, London, New Delhi, Singapore and Washington.D.C: Sage.

Lo, M.L., Pong, W.Y., \& Packey, C.P.M (Eds.) (2005) For Each and Everyone - Caterting for Individual Differences through Learning Studies. Hong Kong: Hong Kong University Press.

Lo, M.L. (2012) Variation Theory and the Improvement of Teaching and Learning, Gothenburg Studies in Educational Sciences 323, Goteborgs Universitet. 
Lo, M.L. \& Marton, F. (2012) Towards a science of the art of teaching: using variation theory as a guiding principle of pedagogical design, International Journal of Lesson and Learning Studies, Vol. 1 No.1.

Locke, T., Alcorn, N and O'Neill, J. (2013), 'Ethical issues in collaborative action research', Educatiojnal Action Research Journal, Vol. 21, No.1.

Marton, F \& Booth, S (1997) Learning and Awareness, Mahwah, New Jersey: Lawrence Erlbaum Associates, Publishers.

Mockler, N. (2014), 'When "research ethics" become "everyday ethics": the intersection of inquiry and practice in practitioner research', Educational Action Research Journal, Vol. 22, No.2.

Peters, R.S. (1966) Ethics and Education, London: Allen \& Unwin.

Peters, R.S. (1973) Aims of Education-a conceptual inquiry, in R.S. Peters (Ed.) The Philosophy of Education, Oxford Readings in Philosophy, Oxford: Oxford University Press.

Stenhouse, L (1975) An Introduction to Curriculum Research and Development, London: Heinemann.

The Humanities Project: An Introduction 1973, revised by Jean Rudduck 1983, Norwich: University of East Anglia for the Schools Council.

Tan, Y.S. (2014), 'Enriching a collaborative teacher inquiry discourse: exploring teachers' experiences of a theory-framed discourse in a Singapore case of lesson study', Educational Action Research Journal, Vol. 22, No. 3. 